\title{
A tradição de linguagem em Gadamer e o professor de química como tradutor- intérprete
}

Robson Simplicio de Sousa robsonsimplicio@hotmail.com orcid.org/0000-0002-4637-5014 (UFTM), Iturama, MG, Brasil

Maria do Carmo Galiazzi mcgaliazzi@gmail.com orcid.org/0000-0003-0513-0018 Universidade Federal do Rio Grande (FURG), Rio Grande, RS, Brasil

\begin{abstract}
RESUMO
Neste estudo, articulamos o conceito de tradição de linguagem de Hans-Georg Gadamer e seus desdobramentos educacionais com a ideia do professor como tradutor-intérprete no ensino de Química. Partimos, estimulados pelo químico Pierre Laszlo, de uma perspectiva ontológica de linguagem, especialmente, a de Hans-Georg Gadamer, filósofo alemão que estabeleceu a Hermenêutica Filosófica com sua obra Verdade e Método de 1960. Iniciamos apresentando elementos que nos ajudam a elaborar compreensões neste texto, ao conceito de tradição de linguagem trazido por Gadamer e em como este conceito repercute no âmbito da Filosofia da Educação. A partir de uma ilustração acerca dos intérpretes da tradição de linguagem feita por Gadamer, foi possível percebermos o professor de Química também como um tradutor-intérprete da tradição de linguagem da ciência que se propõe a ensinar. Assim, traçamos provocações à formação e à atuação do professor de Química e com este olhar buscamos superar o que chamamos de limitação dialógica, limitação histórica e limitação escrita. Consideramos que essas provocações formativas sobre a tradição podem contribuir para a Educação Química, com mais história, mais criticidade, mais subjetividade e experiência dos sujeitos que nela atuam.
\end{abstract}

PALAVRAS-CHAVE: Tradição de Linguagem. Gadamer. Hermenêutica. Tradutor-intérprete. Educação Química. 


\section{INTRODUÇÃO}

Neste artigo apresentamos compreensões teóricas acerca da Hermenêutica Filosófica atribuída ao filósofo Hans-Georg Gadamer (1900-2002) com a intenção de aproximarmos esta perspectiva filosófica da formação e da prática de professores de Química. Em trabalho preliminar percebemos a potencialidade da temática ainda pouco investigada em revistas internacionais da área de Filosofia da Química (SOUSA; GALIAZZI, 2017). Por isso, apresentamos esta temática como uma perspectiva a ser ampliada na formação de professores de Química.

É possível situarmos este estudo teórico dentro da Filosofia da Educação em Ciências (SCHULZ, 2014a) em que somos influenciados pela Filosofia da Linguagem de Gadamer. O que nos motiva a elaborar essas compreensões sobre linguagem na educação Química é a provocação que nos faz Laszlo de que na Química "seria muito importante reivindicar aqui uma ontologia hermenêutica como a de Gadamer: o mundo é linguisticamente constituído e não pode existir desvinculado da linguagem" (LASZLO, 2013, p. 1686, tradução nossa). Estamos tratando de uma perspectiva de linguagem ontológica, constitutiva, que se diferencia da perspectiva instrumental de linguagem (TAYLOR, 2016).

A compreensão humana é, para Gadamer, sempre historicamente determinada e é sempre dada em uma pré-compreensão. Heidegger, uma das principais influências de Gadamer, introduz o conceito do círculo hermenêutico, no qual a interpretação é entendida como uma articulação, desdobramento e desenvolvimento a partir da compreensão. Heidegger passou a ver no círculo hermenêutico a estrutura ontológica da compreensão em si, que pressupõe sempre uma compreensão prévia da realidade, enraizada nas convicções dos seres humanos cotidianos, e sempre se move de maneira circular (LAWN; KEANE, 2011). São estas perspectivas de Gadamer e Heidegger acerca da interpretação e da compreensão que carregaremos ao longo deste texto.

Como apresentaremos a seguir, a hermenêutica filosófica tem nos mostrado elementos provocadores para pensarmos a formação de professores de Química, a atuação dos formadores desses professores e a repercussão dessa formação na educação básica. Entre estes elementos, abordaremos especialmente dois neste texto: o conceito de tradição de linguagem e a ideia do tradutor-intérprete. Ambos reivindicam a conscientização histórica como modo de compreender e ser no mundo imerso na linguagem, o que nos leva a estabelecer articulações com a educação.

Iniciamos este estudo situando aspectos gerais da Hermenêutica Filosófica de Hans-Georg Gadamer a partir de sua obra mais famosa, Verdade e Método, dedicando-nos especialmente ao conceito de tradição e de como este se vincula à ideia de linguagem. Na segunda parte, abordamos alguns desdobramentos deste conceito de tradição na Filosofia da Educação reivindicados por Leiviskä (2015) como necessidade educativa. Na terceira parte, elaboramos argumentos em relação ao professor como tradutor-intérprete da tradição de linguagem. $\mathrm{Na}$ quarta parte, ampliamos essa compreensão de tradição de linguagem e de professor intérprete na Educação Química. Na quinta e última parte, apresentamos as possíveis contribuições mais relevantes deste ensaio. 


\section{UMA COMPREENSÃO DA HERMENÊUTICA DE GADAMER A PARTIR DA OBRA VERDADE E MÉTODO I}

O delineamento histórico de uma posição filosófica como a de Hans-Georg Gadamer é sempre limitado por nossa própria interpretação. Esta é encharcada de pressupostos e preconceitos que nos tomam linguisticamente. A partir de Gadamer, compreende-se a ideia de que para textualizarmos sobre o mundo não é necessário suspender nossos preconceitos. Pelo contrário, é a partir da consciência desses preconceitos que poderemos ampliar o alcance de compreensão. Assim, delineamos a seguir nossa interpretação de elementos gerais da hermenêutica Gadameriana que entendemos que contribuirão para dialogarmos acerca do conceito de tradição e da ideia de tradutor-intérprete nos processos educativos, proposta deste texto.

A obra de Gadamer, Verdade e Método I: traços fundamentais de uma hermenêutica filosófica (2015) apresenta como problema da hermenêutica o fenômeno da compreensão e da maneira de interpretar o que se entende. Este problema não pode se limitar aos métodos das ciências humanas (Geisteswissenschaften), visto que Wilhelm Dilthey (1833-1911) buscava uma equiparação metodológica das ciências humanas às ciências naturais, influenciada pela ideia metodológica da última. Para Gadamer (2015), o problema hermenêutico não se restringe à metodologização das ciências humanas, já que entender e interpretar pertencem a toda experiência do homem no mundo. 0 filósofo propõe uma hermenêutica não como uma doutrina de métodos das ciências humanas, mas para entender o que são as ciências humanas e o que as ligam à experiência de mundo.

De forma a ampliar esta compreensão, Gadamer anuncia suas principais influências que passam pela descrição fenomenológica de Edmund Husserl (18591938), pela abrangência do horizonte histórico de Dilthey e pela articulação entre os dois autores em Martin Heidegger (1889-1976) (GADAMER, 2015). A partir destes filósofos, o hermeneuta busca um conceito de conhecimento e de verdade que correspondam à experiência de interpretação e de compreensão, ao considerar o universo hermenêutico como aquele formado pelos modos como experimentamos uns aos outros, experimentamos as tradições históricas e as ocorrências naturais de existência e de mundo. Por isso, Gadamer reivindica que a verdade nas ciências humanas não pode querer desconsiderar a tradição, mas exigir que sua forma de trabalho adquira uma transparência histórica, além de um relacionamento (diferente da ciência moderna) com os conceitos que ela utiliza, pensando-os não como princípios, mas como o aperfeiçoamento de um acontecimento que já vem de longe (GADAMER, 2015).

Gadamer aposta na tradição histórica como necessária ao fenômeno do compreender. Para ele, a experiência da tradição histórica vai além do que nela se pode investigar, pois ao compreender a tradição, compreende-se para além de textos, adquirirem-se juízos e reconhecem-se verdades. A tradição histórica passava por uma objetivação em pesquisas nas ciências humanas estimulada por Dilthey, o que Gadamer considerava uma superexcitação da consciência de uma mudança histórica, cuja consequência foi apelar para uma ordenação da natureza a partir de sua legitimação naturalizada pelo homem. As expectativas do resultado da experiência da mudança histórica corriam o risco de serem distorcidas por 
ocultação do permanente e que, por isso, Gadamer entendia necessário resgatar este permanente (GADAMER, 2015). Para o autor, a conceitualidade do filosofar nos constitui, assim como somos determinados pela linguagem em que vivemos, em que o filosofar responsável coloca os costumes de linguagem e de pensamento que formam o indivíduo na comunicação de seu mundo (GADAMER, 2015).

É sobre a linguagem como meio pelo qual nos comunicamos acerca de nosso mundo que Gadamer apresenta o que vem a ser uma conversação. Ele a diferencia em conversação autêntica e inautêntica de modo a situar como isto pode ocorrer em nosso cotidiano. Em uma conversação autêntica, não "levamos" uma conversa, não há direcionamento da vontade dos interlocutores. Somos dirigidos por ela, ou seja, uma palavra puxa a outra. Assim, desembocamo-nos e enredamo-nos na conversação que toma seu próprio rumo, encontra seu curso como um acontecimento entre os interlocutores que não a dirigem, mas são dirigidos por ela. A conversação tem seu próprio espírito, que carrega na linguagem utilizada sua própria verdade em que "desvela" e deixa surgir o que é a partir de então (GADAMER, 2015).

Gadamer fala de diálogo, pois é especialmente a partir da linguagem do diálogo que ele constrói os fundamentos de sua hermenêutica filosófica. Os enredamentos nos diálogos têm na linguagem o meio para realização de acordos dos interlocutores e o entendimento sobre aquilo em questão. Gadamer ilustra isto a partir de pessoas que falam línguas diferentes em uma conversa. Para isto, há a necessidade de um tradutor. A figura do tradutor tem sua importância na medida em que ele é responsável por transpor um sentido a ser compreendido para o contexto do outro interlocutor. Portanto, para ele, toda tradução já é interpretação em que a linguagem é o medium ${ }^{1}$ de acordo que é produzido artificialmente através de uma mediação expressa e que, por mais que o tradutor tente exprimir e ser fiel à vida e aos sentimentos do autor, a tradução sempre constituirá uma nova luz ao texto (GADAMER, 2015). O tradutor precisa preservar o sentido, mas levar em conta que este precisa ser compreendido em outro universo de linguagem. Este sentido, portanto, precisa ser interpretado pelo tradutor para ser considerado válido. Ou seja, o caráter de linguagem está nos acordos estabelecidos nos diálogos que é o que Gadamer chama de fusão de horizontes, em que

Horizonte é o âmbito de visão que abarca e encerra tudo o que pode ser visto a partir de determinado ponto. Aplicando este conceito à consciência pensante, falamos então da estreiteza do horizonte, da possibilidade de ampliar o horizonte, da abertura de novos horizontes etc. (GADAMER, 2015, p. 399)

\section{E acrescenta que}

O horizonte é, antes, algo no qual trilhamos nosso caminho e que conosco faz o caminho. Os horizontes se deslocam ao passo de quem se move. Também o horizonte do passado, do qual vive toda vida humana e que se apresenta sob a forma de tradição, que já está sempre em movimento (GADAMER, 2015, p. 402). 
Dentro do diálogo autêntico, o compreender é sempre o processo de fusão desses horizontes, pois, para Gadamer, "compreender é sempre o processo de fusão de horizontes presumivelmente dados por si mesmos" (GADAMER, 2015, p. 404), no qual os interlocutores textualizam ${ }^{2}$ linguisticamente em/a partir de suas tradições históricas, cuja singularidade dos horizontes individuais não se destaca explicitamente. A fusão de horizontes se constitui numa situação interpretativa única, na qual os enredamentos dialógicos em busca de compreensão não pertencem a um ou ao outro interlocutor, mas tornam-se horizonte comum em que as tradições de linguagem se encontram. É por isso que Gadamer diz que, no diálogo com fusão de horizontes, a expressão de uma "coisa" não é somente minha ou de meu autor, mas uma coisa comum a ambos (GADAMER, 2015). Em outras palavras, esta fusão de horizontes se realiza na linguagem, para além de seu sentido instrumental, em que os interlocutores que carregam suas experiências se abrem ao diálogo buscando sentidos compartilhados.

Delineamos, nesta primeira parte, alguns elementos da obra Verdade e Método I de Gadamer que se dedicou ao fenômeno da compreensão não apenas atribuindo-o às ciências humanas, mas ao nosso modo de ser no mundo. Neste compreender como ser no mundo, Gadamer entendia que não é possível desconsiderarmos a tradição histórica que se concretiza na linguagem, à medida que nos enredamos em diálogos autênticos entre passado e presente ou ainda entre interlocutores do presente - que são sempre históricos - em um diálogo cotidiano. Desse modo, o diálogo como busca de (auto)compreensão que acontece na linguagem se constitui como abertura à aproximação de horizontes comuns, que passam a fazer parte de ambos interlocutores enredados no processo dialógico. Até este ponto do texto, foram tratados alguns elementos da obra de Gadamer como compreensão, linguagem, diálogo e fusão de horizontes que nos ajudam a dialogar, a seguir, acerca do conceito de tradição de linguagem e seus desdobramentos nos processos educacionais.

\section{A TRADIÇÃO DE LINGUAGEM EM GADAMER}

Os acordos que emergem do diálogo no plano hermenêutico buscam a compreensão de textos, em que estão postos os traços próprios da linguagem que vêm da existência de uma tradição que é sempre histórica. Para Gadamer, " $a$ vigência da tradição é o lugar onde essa fusão [de horizontes] se dá constantemente, pois nela o velho e o novo sempre crescem juntos para uma validez vital, sem que um e outro cheguem a se destacar explícita e mutualmente" (GADAMER, 2015, p. 404-405). Gadamer ressalta a especial primazia da tradição de linguagem frente a outras tradições, pois, para ele, a tradição de linguagem:

(...) é tradição no sentido autêntico da palavra, ou seja, aqui não nos defrontamos simplesmente com um resíduo que se deve investigar e interpretar enquanto vestígio do passado. $O$ que chegou a nós pelo caminho da tradição de linguagem não é o que restou, mas é transmitido, isto é, nos é dito - seja na forma de tradição oral imediata, onde vivem o mito, a lenda, os usos e costumes, seja na forma de tradição escrita, cujos signos de certo 
modo destinam-se diretamente a todo e qualquer leitor que esteja em condições de os ler. (GADAMER, 2015, p. 504)

E complementa que a essência da tradição de linguagem está na escrita e que esta possui significado hermenêutico (GADAMER, 2015).

O ensinamento de Aristóteles de que "o homem é o ser vivo dotado de logos" foi preservado no Ocidente com o significado de que o homem é o animal racional, ou seja, dotado de racionalidade, vinculando logos à razão, ao pensamento (ROHDEN, 2002). Rohden argumenta, ao trazer elementos do próprio Aristóteles, que logos significa também linguagem, lição que Gadamer aprendeu com Heidegger. Gadamer ampliou sua concepção de linguagem desde Verdade e Método I, em que vinculava linguagem ao "ser o texto", compreendendo a linguagem como aquela que se realiza no diálogo, seja no gestual, seja nos costumes, seja no silêncio, seja na busca de expressão acerca do mundo (ROHDEN, 2002).

Para este texto, tentamos delinear aspectos da tradição de linguagem na Educação Química no plano dialógico-textual, conscientes da possibilidade de emergência de outras tradições de linguagem ao longo desta tentativa. Desse modo, valorizamos a tradição de linguagem escrita por concordarmos com Gadamer que:

\footnotetext{
A tradição escrita não é apenas uma parte de um mundo passado, mas já sempre se elevou acima deste, na esfera do sentido que ela enuncia. Trata-se da idealidade da palavra que todo elemento de linguagem eleva acima da determinação finita e efêmera, própria aos restos de existências passadas. 0 portador da tradição não é este manuscrito como uma parte do passado, mas a continuidade da memória. Através dela, a tradição se converte numa parte do próprio mundo e, assim, o que ela nos comunica pode chegar imediatamente à linguagem. Onde uma tradição escrita chega a nós, não só conhecemos algo individual, mas se faz presente em nossa pessoa uma humanidade passada em sua relação universal. (GADAMER, 2015, p. 505)
}

As interpretações de uma tradição escrita, já constituem uma elevação acima dela, como modo de aprender sobre ela, sobre nós mesmos e, assim, sobre o próprio mundo, numa reinterpretação que já é mudança dessa tradição, nossa e também do mundo. Compreendemos que é por isso que Rohden (2002, p. 231) diz que "ler compreensivamente um texto não é uma atividade arqueológica, nem teleológica asséptica, mas significa tomar parte dele".

Um dos críticos do conceito de tradição de Gadamer é Jürgen Habermas, que entende que ao buscar compreender, na hermenêutica filosófica, a partir de preconceitos herdados de uma tradição não é possível superá-los por uma reflexão condicionada por esta mesma tradição. Neste modo de reflexão, apenas se conserva e se dá visibilidade a uma precompreensão histórica consciente. Já Günter Figal entendia que na hermenêutica de Gadamer apenas se confirma a continuidade da tradição que nos molda e que uma busca de compreensão é transitória, pois a tradição continua a ser efetiva (LEIVISKÄ, 2015).

Gadamer não traça uma definição do conceito de tradição, mas, a partir dele, Leiviskä (2015) distingue dois significados diferentes. O primeiro é tradição como estrutura ontológica que se refere a todo o processo de tradição, um contínuo das influências históricas. Vincula-se à noção Gadameriana de história efeitual, em que 
um contínuo interpretativo de um assunto está precondicionado por suas tradições anteriores e que elas mesmas participam na evolução da tradição atual. A compreensão é afetada tanto pela tradição como tem efeito na tradição, pois cada momento histórico compreende um assunto a partir do ponto de vista de seu próprio lugar na história e, assim, transforma o modo como o assunto é compreendido. O segundo é tradição como um concreto, em que horizontes únicos podem ser encontrados em ações particulares de compreensão através de diferentes articulações do passado. A tradição pode ser vista como um "objeto" de compreensão, embora esteja amarrado à situação particular do intérprete, pois é ele que aborda o objeto a partir de seu lugar único na história. Apresentando uma interpretação do conceito de tradição diferente dos críticos, Leiviskä entende que:

Gadamer não vê a tradição como uma fonte de erro ou dogma que precisa
ser refletidamente superado, mas, ao invés disso, como um modo de ser no
qual nós já nos encontramos e uma fonte infinita de diferentes pontos de
vista e perspectivas contra as quais nossos preconceitos presentes podem ser
postos em jogo. (...) A tradição não é uma força dogmática, ao invés disso, ela
pode ser uma força valiosa de autoconsciência e conhecimento. (LEIVISKÄ,
2015, p. 592)

Iniciamos ressaltando o voltar-se de Gadamer ao conceito de tradição de linguagem, como uma prioridade em relação a outras tradições, pois, o que chegou até nós textualizado linguisticamente, possui em si elementos a partir dos quais interpretamos. Possui um caráter hermenêutico, cuja ideia original não é passível de ser reconstruída como foi elaborada inicialmente, mas está potencialmente aberta às múltiplas interpretações que são influenciadas pelas tradições históricas daquele que interpreta e que se torna parte do mundo e de tradições de linguagem como um concreto e como uma estrutura ontológica.

\section{O CONCEITO DE TRADIÇÃO GADAMERIANO NA FILOSOFIA DA EDUCAÇÃO}

O conceito de tradição em Gadamer esteve isolado das discussões educacionais em função do conservadorismo atribuído à noção de tradição (LEIVISKÄ, 2015). Este conceito está associado a um conservadorismo indesejável que objetiva preservar normas e valores do passado e obter um fundamento normativo para a educação. Contudo, em termos educacionais, não é possível fugir da autoridade da tradição, pois ela se aplica tanto para professores quanto para estudantes que estão imersos em preconcepções tradicionais sem que necessariamente estejam conscientes disso (LEIVISKÄ, 2015).

$\mathrm{Na}$ inconsciência da tradição de linguagem dentro do contexto educacional, estamos condicionados por ela, uma vez que transmitimos uma tradição de linguagem específica construída historicamente, uma tradição de nos apresentarmos de determinado modo como educadores e como estudantes, uma construção curricular de conteúdos "ensináveis" tradicionais e inclusive uma tradição de institucionalização da escola como ambiente em que se educa. Esses fragmentos concretos de tradição compõem ontologicamente a tradição na educação. "A tradição é a base de operação inconsciente que inescapavelmente precondiciona todos os atos e configurações educacionais" (LEIVISKÄ, 2015, p. 594). 
Para Leiviskä (2015, p. 595), "a tradição inevitavelmente tem um significado diferente para cada tempo histórico e, assim, cada geração precisa considerar este significado a partir do ponto de vista de seu lugar único na história". Isto se desdobra em termos educacionais quando:

Educadores como representantes de uma geração prévia são incapazes de dar respostas imediatas aos estudantes à questão de como eles devem compreender e se apropriar da tradição que herdaram. Na verdade, qualquer tentativa de determinar o modo como a tradição será apropriada no futuro significa exceder a autoridade que a educação como forma histórica de ação pode ter. Assim, o que é exigido dos estudantes é um modo de racionalidade que os permita reinterpretar a tradição a qual eles pertencem de forma que revele seu significado genuíno em sua situação histórica única. (LEIVISKÄ, 2015 , p. 595, tradução nossa)

Nossa finitude histórica e nossos limites interpretativos são características únicas que fazem com que as tradições nunca sejam apropriadas da mesma maneira. Isto porque nossa reinterpretação da tradição nunca é solitária, é sempre com outro, de reconhecimento deste outro. As tradições históricas reivindicam considerar o outro nos processos interpretativos, o que nos exige o permanente exercício da escuta, de abertura e de acolhimento ao que o outro expressa, além de (re)análise constante de nossas preconcepções. Sobre isto, Leiviskä interpreta, a partir de Gadamer, que:

(...) a possibilidade de encontrar a alteridade neste modo não está limitada a encontros com textos históricos e outras expressões do passado; ao invés disso, ela é estendida a todas as nossas conversações e diálogos com outros seres humanos que são sempre, em muitos modos, diferentes de nós. (LEIVISKÄ, 2015, p. 599)

O diálogo [e aqui complementamos que é sempre um diálogo imerso numa tradição histórica de linguagem] se constitui na força do próprio educar - que é educar-se - na confrontação do sujeito consigo mesmo, com suas opiniões e crenças, pela condição interrogativa na qual vivemos (HERMANN, 2002). Por isto, a experiência hermenêutica propõe um afastamento do tecnicismo educacional, ao exigir um colocar-se em risco às situações inesperadas, impossibilitando assegurar às práticas educativas uma estrutura estável, que garanta o êxito da ação interventiva (HERMANN, 2002). Hermann alerta que é preciso:

Deixar os que se educam dizer a palavra (a palavra da ciência, do ético, do estético, da dor da poesia) é radicalizar a ideia de que o homem possui linguagem. A abertura de horizontes que o diálogo possibilita permite à educação fazer valer a polissemia dos discursos e criar um espaço de compreensão mútua entre os envolvidos. (HERMANN, 2002, p. 95)

Trouxemos, neste ponto, a perspectiva de que a tradição pré-configura as ações educacionais e que as tradições como "objetos" concretos de linguagem repercutem na tradição ontológica. Ambas são históricas, o que traz aos professores desafios na tentativa de educar novas gerações, já que não se sustenta uma postura autoritária do professor sobre o modo como os estudantes devem tratar das tradições que herdarem. Os herdeiros da tradição, como sujeitos de um tempo histórico único, precisam ser orientados à (re)interpretação de sua herança. Ou seja, aposta-se no ensinar a interpretar como condição educacional, pois a finitude histórica de uma geração pode apenas deixar a interpretação como legado 
à próxima geração. Para isto, é fundamental o diálogo entre aqueles que se educam e educam, buscando a compreensão com sujeitos de tradições históricas de linguagem próprias.

\section{O PROFESSOR COMO TRADUTOR-INTÉRPRETE NO PROCESSO EDUCATIVO}

Dentro de um processo educacional dialógico, podemos traçar elementos que posicionam o professor como tradutor-intérprete de uma tradição histórica de linguagem. Partimos da compreensão de que o professor não usará integralmente a linguagem original de um conhecimento científico no processo educativo, pois o professor se constitui como um intérprete daquele conhecimento que possui uma tradição da qual ele se torna parte por suas experiências acadêmico-profissionais. O conhecimento científico possui uma tradição histórica que o professor, com seus limites de compreensão, inclusive temporais, não consegue abarcar na integralidade. As exatas condições de origem da tradição de um conhecimento científico são inacessíveis ao professor que, dentro de sua finitude, consegue apenas interpretá-las linguisticamente dentro de seu próprio tempo histórico.

Ao compreendermos que a interpretação é linguística, o professor precisa estar consciente de que a linguagem científica não é própria ao estudante, assim como não é própria a ele mesmo e nem se manifesta em sua prática como foi originalmente construída. Trata-se, portanto, de uma interpretação que se mostra por meio da linguagem, mas que dentro das conversações que se estabelecem nos processos educativos não se tem a finalidade de "dominá-la como uma estrutura lógica, mas de manejá-la corretamente" (BERTICELLI, 2004, p. 298).

A partir da ilustração de Gadamer (2015) acerca do tradutor dentro do processo conversacional como aquele que interpreta o mundo sobre seu horizonte de compreensão e que traduz para o outro no diálogo, entendemos possível reconhecer alguns papeis atribuídos ao professor como tradutor em suas ações interpretativas. Alcançamos perceber duas delas que apresentam elementos complementares e relacionados. A primeira se refere à tradução das tradições de linguagem como um concreto do mundo. A segunda se refere à tradução no diálogo sobre as tradições de linguagem no processo educativo.

O professor traduz interpretativamente as tradições de linguagem como um concreto do mundo. Assim como ao tradutor, ao professor interessa uma maior fluência e clareza linguísticas que a interpretação original, pois esta passa a ser reconstituída a partir de seu horizonte de compreensão. No esforço de reconstituição, o professor tenta resguardar a tradição de linguagem original, para a qual traduz, mesmo consciente da distância em que interpreta em relação à origem. Para Gadamer (2015, p. 500), "toda tradução que leva a sério sua tarefa torna-se mais clara e mais fluente que o original". Para o professor, o processo educacional tem por finalidade tornar o mundo mais acessível linguisticamente a partir de novas possibilidades interpretativas. Contudo, o professor-tradutor "tem, muitas vezes, dolorosa consciência da distância que o separa necessariamente do original" (GADAMER, 2015, p. 500), principalmente em termos do contexto histórico no qual se origina a tradição de linguagem que ele interpreta dentro do processo educacional. A tradução se constitui, portanto, em um esforço reconstitutivo em que "só será um verdadeiro reconstituidor aquele tradutor [ou professor] que consiga trazer à linguagem o tema que o texto lhe mostra" 
(GADAMER, 2015, p. 501). Também ao professor cabe conseguir se expressar linguisticamente sobre um tema como este se apresenta para ele, ou seja, uma expressão interpretativa, o que está diretamente vinculado ao modo como se constitui a sua formação.

Entendemos que aqui caiba a segunda possibilidade de interpretação acerca do professor-tradutor, em que o professor traduz interpretativamente a partir das tradições de linguagem no processo educativo dialógico. Nesta forma de tradução, o professor precisa estar inicialmente consciente de que há uma distância inalcançável entre a opinião de outro e a própria, à medida que tenta, no diálogo, colocar-se no lugar do outro, mesmo entendendo que este lugar não pode ser originalmente reconstituído numa integralidade. É por isso que no processo educativo é preciso estar disposto ao acolhimento de outros modos de expressão linguística acerca do mundo e daquilo que é estranho a ambos os interlocutores dentro do fenômeno dialógico. Isto se mostra relevante para que eles possam avaliar contra-argumentos um do outro e que reciprocamente possam modificar seus pontos de vista de forma a chegar a uma linguagem comum, compartilhada. Ou seja, trata-se sempre de uma busca de acordos de conversação na qual o professor-tradutor é aquele que equilibra a tentativa de adequação do encontro entre linguagem conhecida e desconhecida.

A distância entre a opinião do estudante e a do professor não pode ser superada, pois não é possível alcançar integralmente o que cada interlocutor "quis dizer" no dito. Dentro desse processo dialógico-educacional, ambos são intérpretes das expressões linguísticas um do outro, mas não se chega à exatidão do que se expressou numa conversação. O que se pode buscar dentro do processo educacional são acordos interpretativos entre os interlocutores, a fusão de horizontes.

Assim como Gadamer (2015) indica como papel do tradutor na conversação o de colocar-se no lugar do outro na intenção de compreender seu ponto de vista, também o professor precisa permanentemente tentar por-se no lugar do estudante, mesmo não conseguindo reconstituir o ponto de vista original. No processo educativo, é atribuição do professor criar condições para que o estudante também busque colocar-se no lugar do outro no esforço de compreender seu ponto de vista. Há, na disposição ao diálogo autêntico, a provocação para que se estabeleçam acordos à medida que se acolhe a opinião do outro.

O acordo na conversação implica que os interlocutores estejam dispostos a isso, abrindo espaço para acolher o estranho e o adverso. Quando isso ocorre, de ambas as partes e cada interlocutor sopesa os contra-argumentos, ao mesmo tempo, mantém suas próprias razões, pode-se, por uma recíproca, imperceptível e involuntária transferência de pontos de vista (o que chamamos de intercâmbio de opiniões) chegar finalmente a uma linguagem comum (GADAMER, 2015, p. 501).

Nesta perspectiva, o professor estimula dentro do que podemos chamar de círculo interpretativo escolar que se chegue a esses acordos dialógicos. No processo educacional, o professor-tradutor buscará dialogicamente, naquele contexto, o caminho mais adequado em direção ao consenso. O consenso, à medida que considera e reconhece os outros como autores dele, torna-se um compromisso comum. 
Ao professor cabe resguardar o direito da linguagem cotidiana do estudante, ao mesmo tempo em que apresenta também o estranho e inclusive o adverso de sua forma de expressão, para que esta se constitua "uma linguagem que seja adequada não somente a sua língua, mas também àquela do original" (GADAMER, 2015 , p. 501). Assim, o professor-tradutor é aquele disposto a encontrar uma linguagem que seja adequada não somente à língua cotidiana, mas também trazer elementos que a aproximem à tradição de linguagem do conhecimento específico.

Diante desta articulação, expõe-se o professor como um intérprete que está voltado tanto para as questões que permeiam as conversações dialógicas imediatas e cotidianas do contexto escolar, mas também inclinado à reflexão e à mudança de atitude frente ao mundo. Estas se mostram por meio da linguagem e constituem uma preocupação do professor com a própria existência do estudante, o que também é trazido por Hermann (2002) quando ressalta que:

A hermenêutica nos mostra que nem tudo aquilo que é desconhecido é
transformado em conhecido, como pretendia o conceito iluminista de
progresso. E os processos pedagógicos, a despeito do domínio buscado por
diferentes técnicas, trazem consigo o movimento próprio da existência
humana, que é a tensão entre iluminação e encobrimento. (HERMANN, 2002,
p. 88)

Ao recorrer à ideia do tradutor como sujeito que interpreta o mundo linguisticamente entre interlocutores, Gadamer nos abre possibilidades de compreensão de como nos expressamos sobre o mundo em nossos processos formativos como professores. Cotidianamente, realizamos (quase sempre inconscientemente) essas interpretações sobre o mundo. Quando percebemos a figura do professor como tradutor-intérprete do mundo linguisticamente construído, podemos entender que esta constitui sua atribuição mais fundamental. É com o professor e, possivelmente, a partir de suas interpretações acerca do mundo que se modificam muitas das tradições de linguagem. 0 professor está amparado institucionalmente na sociedade para tratar dos modos de construção do conhecimento humano que são expressos por tradições como um concreto. Este tratamento nada mais é do que as interpretações dessas tradições. Portanto, ao professor cabe diretamente a sustentação interpretativa do que permanece e daquilo que se modifica na tradição de linguagem no contexto educacional.

Como já abordamos, o professor propaga diariamente tradições mesmo de forma inconsciente, justamente por não conhecê-las ou não reconhecê-las. Desconhecimento e não-reconhecimento estes que estão vinculados às próprias tradições educacionais em que foi formado. Ao tornar-se consciente delas, entendemos que sua ação de tradução-interpretação no processo educacional pode provocar modificações nas tradições educacionais em que este profissional foi formado e naquela em que ele forma outros sujeitos. É por isso que, ao compreendermos o professor como tradutor-intérprete de uma linguagem, marcamos a ação do professor como aquela que está autorizada a "mexer" na tradição - a partir dela, não aquém dela. Ao utilizarmos os termos que trouxemos a partir de Leiviskä (2015), compreendemos que o professor é, portanto, um ator envolvido diretamente com a tradição no sentido ontológico, pois é a partir dos movimentos interpretativos que este realiza com seus interlocutores acerca de 
tradições como um concreto que emergem interpretações que antes não haviam sido expressas.

\section{A EDUCAÇÃO QUÍMICA E A TRADIÇÃO DA LINGUAGEM}

A Educação em Ciências é antes de tudo Educação, uma ciência humana que tem como foco a ciência natural (SCHULZ, 2014b). Parafraseando esta compreensão de Schulz, a Educação Química é, antes de tudo, uma ciência humana, a Educação, que tem como foco a Química. Como ciência humana, não é possível desconsiderarmos a tradição da Química na Educação Química, mas que esta assuma uma transparência histórica de sua tradição para que isto possibilite o aperfeiçoamento dos acontecimentos históricos. É com o entendimento de que a Química possui uma tradição histórica de linguagem que, ao educarmos sobre esta tradição, estamos também nos educando sobre o mundo. Esta educação não se trata de uma educação com fins e objetivos restritamente definidos, mas como aquela em que buscamos uma autocompreensão imersa nos elementos dessa tradição de linguagem. A partir da consciência de que estamos imersos numa tradição histórica e da busca permanente de sua compreensão é que conseguimos reconhecer verdades e problematizarmos o permanente na própria Química. Este constitui o papel da Educação Química como ciência humana para além do objetivismo da Química como ciência natural.

Na escola, como ambiente intencionalmente construído para a busca de compreensão, estamos cotidianamente lidando com tradições que, quando ocultadas pelo permanente em busca de uma atualidade que mais esconde do que revela, limita a fusão de horizontes em diversos níveis. Podemos destacar algumas dessas limitações do Ensino de Química que buscamos superar. À primeira, podemos chamar de limitação dialógica. A tradição curricular aliada à tradição escolar de "dar conta" dos conteúdos curriculares ou ainda de "dominá-los" em nome de um "produtivismo escolar" limita que se constituam diálogos autênticos em sala de aula. O diálogo é ocultado em nome do objetivismo de uma dominação de conteúdos pelo professor que, sob influência da comunidade disciplinar, é leal ao paradigma que norteia mais ao cientista do que ao professor (SCHULZ, 2014b). Em outras palavras, sem diálogo em sala de aula não há a possibilidade de fusão dos horizontes de compreensão dos interlocutores.

Retomamos a provocação inicial de Laszlo que nos abriu a possibilidade de percebermos a linguagem em uma perspectiva ontológica. Para ele, a aprendizagem engloba que os estudantes conheçam profundamente uma nova linguagem. Assim, os professores de Química "são guias linguísticos, eles são intérpretes. Eles ensinam seus estudantes como criar frases químicas bem formadas" (LASZLO, 2013, p. 1682).

Ao entendermos o professor de Química como tradutor-intérprete da tradição de linguagem da Química, estamos apostando que sua formação precisa contemplar mais fortemente aspectos da tradição histórica da Química e da tradição da própria formação de professores, para que os professores se tornem vinculados à comunidade de professores em Ciências/Química, não reféns de uma ciência presenteísta e dogmática que ensinam. Ao estarem identificados com essa comunidade de professores que conhecem a tradição da linguagem da Química, poderão perceber outras possibilidades de compreensão e elaboração da própria 
ciência ensinada, conscientes de que eles marcam e são marcados por esta tradição a qual se dedicam.

À outra limitação do Ensino de Química que percebemos chamamos de limitação histórica. Em nome de uma atualidade de desenvolvimento científico, a tradição histórica da Química é pouco contemplada na educação básica, também consequência da limitação histórica em cursos de formação de professores de Química. Trata-se de limitar a formação de/para consciência histórica, já que na tradição da formação de professores de Química pouco se aposta no aprofundamento de fusão de horizontes entre interlocutores do passado e do presente. Por isso, estamos imersos em uma tradição do ensino de Química ahistórico que, por pouco nos dedicarmos à história, estamos "vendados" pela atualidade como aquilo que importa de imediato. Assim, a limitação histórica da Química dentro de seu ensino nos torna "presos" em uma atualidade que parece imutável e inquestionável.

Na busca de superar a limitação de tradição histórica na Educação Química leva à necessidade de registro dessa interpretação da história que está essencialmente na escrita. Falamos, então, de uma limitação escrita. A própria tradição histórica reivindica a escrita como registro das interpretações históricas que passam a fazer parte de uma atualidade que não têm o caráter de estabelecimento de certos ou errados configurados por verdades a-históricas e imutáveis. É justamente pelo registro escrito que, ao textualizarmos sobre o mundo, podemos compreendê-lo por ampliação dele. Para Gadamer:

[...] a escrita ocupa o centro do fenômeno hermenêutico, na medida em que, graças ao escrito, o texto adquire uma existência autônoma, independente do escritor ou do autor, e do endereço concreto de um destinatário ou leitor. De certo modo, o que é fixado por escrito se eleva aos olhos de todos para uma esfera de sentido na qual pode participar todo aquele que esteja em condições de ler. (GADAMER, 2015, p. 507)

Assim, a tradição escrita reivindica uma autonomia de textos que pela escrita estão potencialmente disponíveis para interpretação e questionamentos. Se não há este registro por meio da escrita no ensino de Química, reforça-se a impossibilidade de questionamento das tradições de linguagem da Química, bem como reforça a impossibilidade à abertura interpretativa de fenômenos sobre os quais professores, estudantes e pesquisadores em Química podem ser provocados a melhor compreender.

Um aspecto que nos parece central à compreensão e à superação das limitações anteriores está justamente na formação de professores de Química. As limitações dialógicas, históricas e de escrita na formação de professores de química não favorecem que isto seja levado ao contexto escolar como posição filosófico-educacional do professor de Química tradutor-intérprete da tradição de linguagem da Química. Expressar essas limitações na formação de professores e tomar consciência delas constituem movimentos iniciais em busca de superações como comunidade de Educadores em Química.

Assim, se quisermos aprender a partir da tradição de linguagem da Educação Química que temos, é preciso apostarmos na formação de professores de Química conscientes de suas limitações e que busquem compreender como chegaram até aqui. Entendemos que esta formação reivindica disposições de formadores de 
professores de química e de estudantes de licenciatura para a busca de superação dessas limitações com vistas a ampliá-las e com a compreensão de uma tradição histórico-dialógica registrável da Química em fusão com uma centralidade filosófico-educacional. Consideramos que essas provocações formativas sobre/à tradição podem contribuir à Educação Química com mais história, mais criticidade, mais subjetividade e experiência dos sujeitos que nela atuam.

\section{CONSIDERAÇÕES FINAIS}

Apresentamos neste ensaio aspectos gerais da Hermenêutica Filosófica de Gadamer especialmente o conceito de tradição de linguagem. Traçamos alguns elementos da obra do filósofo como compreensão, linguagem, diálogo e fusão de horizontes que nos ajudaram a dialogar sobre a tradição de linguagem, ressaltando a importância de nos processos educacionais estarmos abertos às múltiplas interpretações das tradições históricas daqueles que interpretam. Essas interpretações linguísticas daqueles que educam e se educam se tornam parte de seu próprio mundo e de suas tradições de linguagem como um concreto e como ontológicas.

O professor interpreta e propaga tradições educacionais mesmo de forma inconsciente, pois não pode reconhecer inteiramente sua vinculação às próprias tradições. A ação de tradução-interpretação do professor no processo educacional pode provocar modificações nas tradições educacionais em que este profissional foi formado e naquela em que ele forma outros sujeitos. O professor é o intérprete da tradição de linguagem no contexto educacional, autorizado a "mexer" na tradição - a partir dela, não aquém dela.

No contexto especificamente da Educação Química, reivindicamos as disposições de formadores de professores de Química e de estudantes de licenciatura à percepção de que estamos imersos em uma tradição históricodialógica que nos exige o exercício da escrita, o voltar-se à história da Química e à história da formação de professores (também, mas não apenas, de professores de Química). Este constitui o modo como chegamos até aqui: a nossa tradição de linguagem como educadores em Química. Entendemos que este diálogo com o passado e o presente repercuta numa disposição filosófico-educacional de diálogo no contexto universitário e escolar para a formação de intérpretes, cujas textualizações sobre o mundo afetem também suas próprias existências. 


\title{
Gadamer's linguistic tradition concept and a chemistry teacher as a translator- interpreter
}

\begin{abstract}
In this study, we articulate Hans-Georg Gadamer's linguistic tradition concept and its educational repercussion with the idea of the teacher as translator-interpreter in Chemistry teaching. Our starting point is motivated by the chemist Pierre Laszlo, who follows an ontological perspective of language, especially Gadamer's, a German philosopher who established the Philosophical Hermeneutics with his 1960's work Truth and Method. We present elements that help us to dedicate to the concept of linguistic tradition brought by Gadamer and in how this concept reverberates in the field of the Philosophy of Education. From Gadamer's illustration about the interpreters of the linguistic tradition it was possible to perceive the Chemistry teacher also as a translator-interpreter of the linguistic tradition of science that he intends to teach. Thus, we draw provocations to the formation and performance of the Chemistry teacher while we try to seek to overcome what we call dialogic limitation, historical limitation and writting limitation. We consider that these formative provocations about the tradition can contribute to the Chemistry Education with more history, more criticalness, more subjectivity and experience of the subjects that work in it.
\end{abstract}

KEYWORDS: Linguistic Tradition. Gadamer. Hermeneutics. Translator-Interpreter. Chemistry Education. 


\section{NOTAS}

1. Rohden (2002) ressalta que Medium, na proposta de Gadamer, não deve ser compreendido como meio (Mittel) no sentido instrumental (nomear), mas como meio no sentido de "Iugar, espaço, meio-ambiente, circunstância, centro, modo de algo ser e realizar-se" (ROHDEN, 2002, p. 227).

2. Dimitri Ginev (2013) entende que textualizar significa criarmos dentro do texto questionamentos intrínsecos incompletos, mas relativamente autônomos, que continuem abertos à contextualização e questionamento posteriores.

3. Gadamer (2015) nos traz o princípio da história efeitual, sobre o qual interpretamos que para compreendermos os fenômenos históricos, precisamos considerar o efeito desses fenômenos na história da investigação dos mesmos, não no sentido de uma investigação histórica paralela à compreensão do fenômeno, mas a necessidade de estarmos conscientes de que o fenômeno histórico que buscamos compreender possui um efeito na própria busca de compreensão que torna-se parte da interpretação. Trata-se de um distanciamento que Gadamer coloca em relação ao objetivismo histórico, que, segundo ele, "oculta o emaranhado histórico-efeitual em que se encontra a própria consciência histórica" (GADAMER, 2015, p. 398), que leva a uma postura imediatista do fenômeno e faz com que esqueçamos metade do que ele realmente é, a verdade desse fenômeno.

4. Para Sjöström (2007), o objetivismo representa a visão de que os fatos científicos são independentes do contexto no qual são observados.

5. Utilizamos o termo presenteísta a partir da expressão presenteísmo utilizada por Chassot (2011), com o sentido de tratamos o ensino de química como um ensino focado no "presente" em que pouco nos voltamos à tradição histórica para compreendermos o "presente" e projetarmos o "futuro".

6. Chassot já na década de 90 utilizava o termo "a-histórico", hoje dicionarizado, para tratar o ensino médio como contrário à história, anistórico, alheio à história (CHASSOT, 1995).

\section{AGRADECIMENTOS}

À Coordenação de Aperfeiçoamento de Pessoal de Nível Superior.

\section{REFERÊNCIAS}

BERTICELLI, I. A. A origem normativa da prática educacional na linguagem. Ijuí: Unijuí, 2004. 512 p.

CHASSOT, A. Para que $(m)$ é útil o ensino? Alternativas para um ensino (de Química) mais crítico. Canoas: Ed. Da Ulbra, 1995. 189 p.

CHASSOT, A. Alfabetização científica: questões e desafios para a educação. 5. 
GADAMER, H.-G. Verdade e método I: traços fundamentais de uma hermenêutica filosófica. 15. ed. Petrópolis: Editora Vozes, 2015. 631 p.

GINEV, D. Science Teaching as Educational Interrogation of Scientific Research. Educational Philosophy and Theory, v. 45, n. 5, p. 584-597, 2013. Disponível em: http://www.tandfonline.com/doi/abs/10.1080/00131857.2013.765793. Acesso em: 20 ago. 2017.

HERMANN, N. Hermenêutica e educação. Rio de Janeiro: DP \& A, 2002. 110 p.

LAWN, C.; KEANE, N. The Gadamer Dictionary. A\&C Black, 2011.

LASZLO, P. Towards teaching chemistry as a language. Science \& Education, v. 22, n. 7, p. 1669-1706, 2013. Disponível em: https://link.springer.com/article/10.1007/s11191-011-9408-6. Acesso em: 20 ago. 2017.

LEIVISKÄ, A. The Relevance of Hans-Georg Gadamer's Concept of Tradition to the Philosophy of Education. Educational Theory, Medford, v. 65, n. 5, p. 581-600, 2015. Disponível em:

http://onlinelibrary.wiley.com/doi/10.1111/edth.12135/abstract. Acesso em: 20 ago. 2017.

ROHDEN, L. Hermenêutica filosófica: entre a linguagem da experiência e a experiência da linguagem. São Leopoldo: Ed. Unisinos, 2002. 317 p.

SCHULZ, R. M. Rethinking science education: Philosophical perspectives. IAP, 2014a. 297 p.

SCHULZ, R. M. Philosophy of Education and Science Education: A Vital but Underdeveloped Relationship. In MATTHEWS, M. R. (Ed.). International Handbook of Research in History, Philosophy and Science Teaching. Dordrecht: Springer, 2014b, p. 1259-1316.

SJÖSTRÖM, J. The discourse of chemistry (and beyond). HYLE-International Journal for Philosophy of Chemistry, v. 13, n. 2, p. 83-97, 2007. Disponível em: http://www.hyle.org/journal/issues/13-2/sjostrom.pdf. Acesso em: 20 ago. 2017. ciências: possibilidades à educação química. Alexandria: Revista de Educação em Ciência e Tecnologia, Florianópolis, v. 10, n. 2, p. 279-304, nov. 2017. 
TAYLOR, C. The Language Animal: The Full Shape of the Human Linguistic Capacity. Harvard University Press, 2016. 352 p.

Recebido: 20 nov. 2017

Aprovado: 20 mar. 2018

DOI: $10.3895 /$ actio.v3n1.7431

Como citar:

SOUSA, R. S.; GALIAZZI, M. C. A tradição de linguagem em Gadamer e o professor de química como tradutor-intérprete. ACTIO, Curitiba, v. 3, n. 1, p. 268-285, jan./abr. 2018. Disponível em:

$<$ https://periodicos.utfpr.edu.br/actio>. Acesso em: XXX

Correspondência:

Robson Simplicio de Sousa

Avenida Rio Paranaíba, n. 1229, Centro, Iturama, MG, Brasil.

Direito autoral: Este artigo está licenciado sob os termos da Licença Creative Commons-Atribuição 4.0

Internacional.

(c) (1) 